\title{
Micro Econometric Analysis of Determinants of Occupational Choice in Algeria
}

\author{
Moundir Lassassi, Nacer-eddine Hammouda \\ Research Centre in Applied Economic for Development (CREAD), Algiers, Algeria
}

\begin{abstract}
A review of the literature on the issue of labor market participation and occupational choice allows to see that researches on this one turned more on developed countries. In underdeveloped countries, including Algeria, the determinants of participation in economic activity and individuals' occupational choice remain understood, despite their economic and social importance, since the degree of economic vulnerability and social development is strongly correlated with the occupied job. This work is not concerned with income from the labor market but rather the process that takes place upstream, that is to say, the integration into the labor market. This paper will study the labor market functioning by analyzing the supply and demand of labor. So the first step is to analyze the participation determinants in economic activity and in a second stage to determine the role of individual characteristics, in particular human capital for the tenure choice. The aim of this work is to answer the following questions: (1) What are the factors that influence individual's participation in the labor market? Is there a difference between men and women? (2) What are the occupational choice determinants of an individual on the labor market? Is this the same factors for men and women? (3) What are the causes of failure in the labor market? To answer all the concerns, authors have exploited the employment surveys conducted by the National Office of Statistics (NOS) from Algerian households (employment surveys 1997 and 2007). For processing and data analysis, authors applied several econometric techniques: models of discrete choice (binary logistic regression) and segmentation techniques. Four major findings emerged from this study: First, authors note that women's participation in economic activity is following logic quite different from that of men. For women, the education and training determine the participation in the labor market. For men, it is rather the age that determines participation. The second result concerns the effect of the sex variable; the latter has very important effect on the first phase of participation in economic activity. In the second phase (being busy), the effect of this variable is less important. The third result indicates the human capital importance in the positioning in the various segments of the labor market and improving the job situation. The fourth result is dysfunction in the labor market due to the mismatch between characterized supply by a population increasingly educated and labor demand characterized by job creation increasingly unqualified.
\end{abstract}

Keywords: human capital, labor market, occupational choice, discrete choice model, Algeria

Moundir Lassassi, statistician-economist, Research Centre in Applied Economic for Development (CREAD), Algiers, Algeria. Nacer-eddineHammouda, senior researcher, Statistician-Economist, Research Centre in Applied Economic for Development (CREAD), Algiers, Algeria.

Correspondence concerning this article should be addressed to Moundir Lassassi, Research Centre in Applied Economic for Development, Street Djamel Eddine El-Afghani-El Hammadia Bouzareah, Algiers, Algeria. E-mail: moundir81m@yahoo.fr. 


\section{Introduction}

Among the theories which relate the work on the youth labor market and integration into working life, included are the human capital theory (Becker, 1993), the filter theory (Spence, 1973, 1974; Arrow, 1973), the job search theory, and wage reservation theory. All works on employability are part of one or other of these theories. The insertion is a complex process and very different in different person's concerned categories (M. Vernières, 1997). For the human capital theory, income is function of the classification, determined by human capital accumulation. Hence, individuals invest in their own capital to increase their labor productivity and thus their income. In this theory, employees are not the result of supply and demand law, but on the capital in professional skills yield. These skills can be innate or acquired through training as well as other behaviors that contribute to increased productivity (Tremblay, 1997). The relation between education and wages is not always significant, as productivity-wage relation. Lazear (1981) explained that wages increase with seniority, even if productivity does not increase. Tremblay noted that in addition to the classical analysis framework, individuals can make other investment types such as investment in labor market knowledge, the acquisition of information on the employment, geographical displacement to get the best job opportunities, accepting a lower paid job. He made two remarks on the human capital theory. The first is that investment in human capital is age decreasing function, because older you are, less time is available to grow that capital. The second is that wage gains are increasing at a decreasing rate with age. For Eicher (1979), the human capital theory does not prove that productivity is totally linked to the training level. Proponents of this theory have been incorporating other variables in the basic model to explain the level of income. The added variables are age, sex, region, occupation, and working hours. Vincens (1998), meanwhile, noted that the human capital theory can have explanatory power in a system where employees are flexible and the overall unemployment is low. In the case of Africa, a considerable number of studies have applied the mincerien model (Mincer, 1974) or its variants (Schultz, 2004; Psacharopoulos \& Patrinos, 2004; Kuépié, Nordman, \& Roubaud, 2006) and showed significant yields and positive education years. The role of education is important, because it determines the individual access to the most profitable sectors (formal sector, public sector) in labor market (Kouamé, 1999; Brilleau, Roubaud, \& Torelli, 2004; Lachaud, 1998). In addition, low investment in human capital can lead to low participation in the labor market, if the expected wage is below the reservation wage.

Some studies have investigated the women situation in the labor market after childbirth. Newel and Joshi (1986) and Perry (1988) argued that many women know the transition from working full time to part-time employment. Other studies show that many of them live transition periods in their careers by moving to a lower employment in terms of quality, responsibility, and compensation (Newel \& Joshi, 1996), or simply lose their jobs (Desai \& Waite, 1991; Rönsen \& Sunström, 1996; Wetzels, 1999). Many studies have tried to take into account the endogeneity potential of fertility variables and labor supply which led to three sets of results. If the first group consists of studies which tend to confirm the negative effect thesis of fertility on labor supply (Smith-Lovin \& Tickamyer, 1978), the other two tend to disprove this thesis. Indeed, some studies have led to a reduction of this negative effect (Waite \& Stolzenberg, 1976) and this broadly without this effect disappears (Chevalier \& Viitanen, 2001). The third study group says the disappearance of the negative effect in favor of a positive effect. Chevalier and Viitanen (2001) concluded that not only the negative effect is of short duration, but in the long term, giving birth during adolescence increases the labor supply levels, wages, and experience reducing the likelihood live in poverty. 
In this study, it is not interest income from the labor market but rather the process that takes place upstream, that is to say, the integration into the labor market. It is therefore in this work to analyze the share determinants of men and women participation in economic activity and secondly to determine the role of individual characteristics in the tenure choice. The work has been structured into three parts: The first is the background; the second is data sources containing analysis of the labor supply, labor demand analysis, operation analysis of the labor market, recruitment mode (channel) of employees in Algeria labor demand analysis; the third is conclusions.

\section{Background}

Before any analysis of the labor market, it is important to begin by presenting the main indicators: participation rates, unemployment rates, and occupancy rates.

Table 1

Key Indicators of Labor Market in 2013

\begin{tabular}{|c|c|c|c|}
\hline & Male & Female & Total \\
\hline \multicolumn{4}{|l|}{ Participation rates in the labor force (participation rate) } \\
\hline 15 years and over & 69.5 & 16.6 & 43.2 \\
\hline $15-24$ years & 45.3 & 10 & 27.9 \\
\hline \multicolumn{4}{|l|}{ Employment population ratio } \\
\hline 15 years and over & 63.7 & 13.9 & 39 \\
\hline $15-24$ years & 35.5 & 6 & 21 \\
\hline 25 and over & 73.8 & 16.6 & 45.4 \\
\hline \multicolumn{4}{|l|}{ Unemployment rate } \\
\hline All & 8.3 & 16.3 & 9.8 \\
\hline Youth (16-24 years) & 21.6 & 39.7 & 24.8 \\
\hline Adults $(25$ years +$)$ & 5.5 & 12 & 6.8 \\
\hline \multicolumn{4}{|l|}{ Unemployment rate by educational level } \\
\hline Uneducated & 2.2 & 5.5 & 2.7 \\
\hline Primary & 6.4 & 9.7 & 6.7 \\
\hline Medium & 10.4 & 17.3 & 11.1 \\
\hline Secondary & 7.9 & 16.0 & 9.7 \\
\hline Higher & 9.4 & 19.2 & 14 \\
\hline$\%$ of youth aged $15-24$ in either the workforce or school & 8.8 & 34.6 & 21.5 \\
\hline
\end{tabular}

Source: National Statistics Office (2013).

The first conclusion that emerges from Table 1 is the low participation of women in the labor market. The participation rate of women aged from 15 and over is $16.6 \%$. The second conclusion is that the employment rate is relatively low, less than $39 \%$ of 15 years and older population. Despite the growth of employment rate in recent years, it has not sufficient impact on boosting the labor market.

The third finding is that the young people of 15 to 24 years are affected most from this situation of the labor market - the rate of youth unemployment is three times higher than adults. The situation is more complex for women. Unemployment affects more women than men; the unemployment rate for women is 2.35 times higher than that of men. This brings to say that there is a double discrimination on the integration of youth into the labor market and greater discrimination against women. Unemployment affects more graduates. The unemployment rate for higher education graduates is $14 \%$, this means that one graduate in seven is unemployed after leaving university. The proportion is higher for girls, where one girl of five found herself unemployed 
against one boy of 10 . Another more dramatic reality is that $21.5 \%$ (one over five) of the youth are neither in the labor force nor in school. This proportion is higher for girls, $34.6 \%$ of girls are neither in the labor force nor school against $8.8 \%$ for boys.

\section{Data Sources}

The National Office of Statistics (NOS) carries out an annual households sample survey on labor force. This survey aim is to measure levels of employment and unemployment and their main characteristics relative to a given reference period. The name has changed over time (labor and demography, labor, employment and income, employment), but the principle remains the same - capture in detail the characteristics of the available workforce. This type of survey is carried out in Algeria since 1982. The frequency of these surveys has also evolved over time (annually, semiannually, and quarterly), but most often it is a single pass over a year that has been carried out at different periods of reference. This study used the 1997 and the 2007 employment survey. The sample of 1997 employment survey is taken from a master sample which is taken from the General Census of Population and Housing (RGPH) of 1987, while for 2007 the employment survey sample master is from the RGPH 1998. Employment surveys of 1997 and 2007 were conducted during October/November with reference period of the last week of September.

The sample size varies. For the employment survey of 1997, the sample size is about 7,000 households, while for the 2007 it is 14,866 ordinary households located throughout the country.

\section{Analysis of the Labor Supply}

Analysis of the educational career of the working population. In this part, authors study the labor supply through monitoring the educational generation paths and analysis of the participation determinants in the workforce.

Table 2

Distribution of Labor Force Generation by Education Level

\begin{tabular}{|c|c|c|c|c|}
\hline Education/Training & Before 1972 & 1973-1977 & 1978-1982 & Total \\
\hline \multicolumn{5}{|l|}{ Men } \\
\hline Uneducated & 19.9 & 3.6 & 2.9 & 11 \\
\hline Primary & 30.8 & 14.8 & 16.2 & 24.1 \\
\hline Medium untrained & 17.6 & 31.1 & 34.6 & 27.8 \\
\hline Medium with vocational training & 4.7 & 8.7 & 9.4 & 7.6 \\
\hline Secondary education untrained & 13.6 & 24 & 18.7 & 16.1 \\
\hline Secondary education with vocational training & 3.9 & 6.6 & 6 & 4.5 \\
\hline Higher & 9.5 & 11.2 & 12.2 & 8.9 \\
\hline Total & 100 & 100 & 100 & 100 \\
\hline \multicolumn{5}{|l|}{ Women } \\
\hline Uneducated & 22.4 & 5.6 & 3.1 & 11.7 \\
\hline Primary & 15.3 & 8 & 6.2 & 11.4 \\
\hline Medium untrained & 9.5 & 9.8 & 8.3 & 10.4 \\
\hline Medium with vocational training & 4.2 & 4.9 & 7.8 & 7.3 \\
\hline Secondary education untrained & 17.7 & 13.6 & 7 & 13.3 \\
\hline Secondary education with vocational training & 8.6 & 18.2 & 17.1 & 13 \\
\hline Higher & 22.3 & 39.9 & 50.5 & 32.9 \\
\hline Total & 100 & 100 & 100 & 100 \\
\hline
\end{tabular}

Source: National Statistics Office (2007). 
Analysing Table 2 above, it can be seen that the new cohorts continue their study and come increasingly to the universities as opposed to older generations. This means that there are more and more educated people entering the labor market. The proportion of girls who come to the high level is higher than boys for different generations.

Analysis of educational cohort background (1978-1982). The following Table 3 shows the educational cohort background, it is those born between 1978 and 1982. In 2007, they are aged between 25 and 29 years.

Table 3

Educational Background of the Generation From 1978 to 1982 Number in Thousands

\begin{tabular}{lcllccr}
\hline & Output rate & Rate of passage & Staff & Output & Followed vocational training & $\%$ \\
\hline Total & $9.09 *$ & 90.91 & 3,398 & 309 & 1 & 0.39 \\
Primary & 17.39 & 80.87 & 3,089 & 591 & 28 & 4.78 \\
Medium & 34.81 & 52.64 & 2,498 & 1,183 & 248 & 20.99 \\
Secondary & 22.37 & 42.21 & 1,315 & 760 & 244 & 32.06 \\
Higher & 16.33 & & 555 & 555 & 46 & 8.37 \\
Boys & 3.38 & 96.62 & 1,748 & 59 & 0 & 0 \\
Primary & 16.19 & 83.19 & 1,689 & 283 & 14 & 5.09 \\
Medium & 42.85 & 46.69 & 1,405 & 749 & 157 & 20.92 \\
Secondary & 23.80 & 36.59 & 656 & 416 & 98 & 23.68 \\
Higher & 13.73 & & 240 & 240 & 13 & 5.42 \\
Girls & 15.14 & 84.86 & 1,651 & 250 & 1 & 0.48 \\
Primary & 18.59 & 78.02 & 1,401 & 307 & 14 & 4.50 \\
Medium & 26.29 & 60.29 & 1,093 & 434 & 92 & 21.10 \\
Secondary & 20.84 & 47.80 & 659 & 344 & 145 & 42.17 \\
Higher & 19.08 & & 315 & 315 & 33 & 10.63 \\
\hline
\end{tabular}

Note. * These are not in school. Source: National Statistics Office (2007).

Before starting, it is important to note that since higher education reform was in 1971, authors observed an exponential growth in numbers of academics. Currently, the number of enrolled students in universities is more than 1.2 million students and the graduate number is 250 thousand trained by the Algerian universities. On this generation of 3.4 million people, more than $9 \%$ had never attended school. The proportion of girls who have never attended school is higher (15.14\%) than boys (3.38\%); $16.33 \%$ come to the next level, or one over six, so there is a very high attrition throughout the school cycle. The loss is greater for boys than that for girls. In fact, for boys those arriving at the top level are $13.73 \%$ against $19.08 \%$ for girls. This means that over $83 \%$ leave without diploma (more than $86 \%$ for boys and $81 \%$ for girls). For those who were enrolled but did not reach the higher level, more than $79 \%$ did not follow vocational training after leaving school. This proportion is $81.4 \%$ for boys and $76.8 \%$ for girls. From these results, authors ask for the future of these people who are excluded from the education system without any qualifications and who do not attend any training after leaving school.

Impact of individual characteristics for participation in working life. The following figure represents the procedure that was followed in the econometric modeling. Authors have structured this analysis into three steps. In the first step, authors worked on the total population (active and inactive), with the aim to determine the impact of individual characteristics for participation in economic activity by applying a binary logistic 
regression on the population of working age (15-64 years) issued of the employment survey 2007. In a second step, authors worked on the employed population, in order to determine the role of individual characteristics for effective participation in economic production. In a third step, authors worked only on the employed population and have determined the influence of individual characteristics in the choice of tenure status by applying a multivariate analysis such as segmentation.

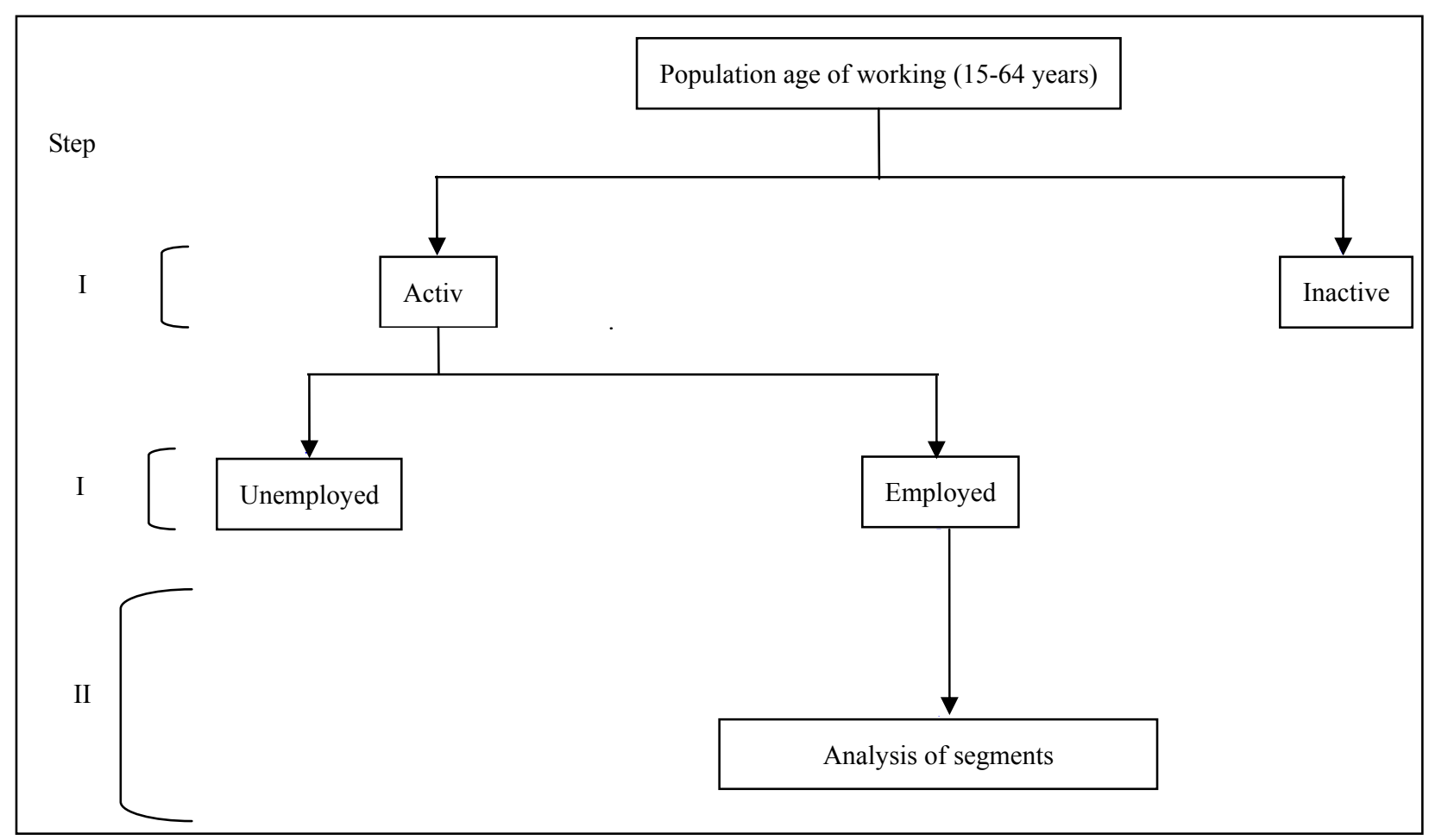

Figure 1. Illustration of the approach

Participation in economic activity is the first phase of the integration process into the labor market. It helps to understand the labor market in terms of availability or unavailability of individuals to participate in economic production. This is a first step in determining the individual characteristics influence of a person to be active in the labor market. For this, authors applied a binary logistic regression analysis on the population of working age (15-64 years) (Figure 1) issued from the employment survey 2007, conducted among households. The decision to participate in the labor market can be formalized by a discrete choice structure where individual $i$ chooses $\left(Y_{i}=1\right)$ or not $\left(Y_{i}=0\right)$ to participate in the labor market. ${ }^{1}$

The general model is written as follows.

$$
Y_{i}=\beta_{\mathrm{o}}+\beta X_{i}+\varepsilon_{i}
$$

The model is estimated separately for men and women.

$$
Y_{i K}=\beta_{\mathrm{oK}}+\beta_{K} X_{i k}+\varepsilon_{i k}
$$

where $Y_{i k}(k=h, f)=1$ or 0 , observed value of participation for individual $i$ respectively for men $(h)$ and women $(f) ; X_{i k}$ means a vector of individual characteristics; $\beta_{k}$ means a vector of estimate parameters; and $\varepsilon_{\mathrm{ik}}$ means an error term.

\footnotetext{
${ }^{1}$ In this work, authors excluded students in the labor force since they have characteristics and different behaviors from the rest of the population economically inactive.
} 
Econometric modeling has highlighted the gender variable as the primary factor that determines the availability or unavailability of a person to participate in economic activity. The results show that men are more likely to be active in the labor market than women; a man is 43.47 times more likely to be active against a woman. Human capital is an important factor for the participation of a person to economic activity. This work measured human capital by education and vocational training level and constructed a synthetic variable combining the two variables, with the aim to measure, at the same time, the importance of education and vocational training to participate in economic activity by comparing people who have the same education (for medium and secondary levels), and the difference between those who have received vocational training and those who have not followed.

Table 4

Determinants of Participation in Labor Force

\begin{tabular}{|c|c|c|c|c|}
\hline Variables* & $\mathrm{B}$ & S.E. & Sig. & $\operatorname{Exp}(B)$ \\
\hline \multicolumn{5}{|l|}{ Sex } \\
\hline \multicolumn{5}{|l|}{ Male (ref) } \\
\hline Female & -3.760 & 0.030 & $* * *$ & 0.023 \\
\hline \multicolumn{5}{|l|}{ Level of education training } \\
\hline \multicolumn{5}{|l|}{ No education (ref) } \\
\hline Primary & 0.235 & 0.041 & $* * *$ & 1.264 \\
\hline Medium untrained & 0.315 & 0.044 & $* * *$ & 1.371 \\
\hline Medium with vocational training & 1.364 & 0.069 & $* * *$ & 3.912 \\
\hline Secondary education without training & 0.819 & 0.050 & $* * *$ & 2.268 \\
\hline secondary education with vocational training & 1.979 & 0.067 & $* * *$ & 7.236 \\
\hline Higher & 3.141 & 0.062 & $* * *$ & 23.116 \\
\hline \multicolumn{5}{|l|}{ Age } \\
\hline \multicolumn{5}{|l|}{$15-24$ (ref) } \\
\hline $25-34$ & 0.576 & 0.037 & $* * *$ & 1.778 \\
\hline $35-44$ & 0.908 & 0.041 & $* * *$ & 2.480 \\
\hline $45-54$ & 0.626 & 0.046 & $* * *$ & 1.871 \\
\hline $55-64$ & -0.971 & 0.053 & $* * *$ & 0.379 \\
\hline \multicolumn{5}{|l|}{ Stratum } \\
\hline \multicolumn{5}{|l|}{ Urban (ref) } \\
\hline Rural & -0.123 & 0.028 & $* * *$ & 0.884 \\
\hline Constant & 0.347 & 0.019 & $* * *$ & 1.415 \\
\hline
\end{tabular}

Note. * Variables are presented as their coming in the model. Source: National Statistics Office (2007).

The results (Table 4) show firstly that the probability that a person is active increases with the evolution of its education. On the other hand, among those having the same level of education, those who received vocational training are more likely to be active.

The probability of a person's participation in the economy evolves according to the person age. This probability is less important for young people aged between 15 and 24 years and persons aged between 55 and 64. In contrast, people aged between 35 and 44 years are more inclined to join the labor market. Finally, it is important to note that people who live in rural areas are less likely (1.13 times less) to be active in the labor market compared to those living in urban areas. 
The contribution of the variable "sex" in the explanatory power of the model is very important compared to other explanatory variables; the variable "sex" alone contributes $83.28 \%$ in the explanatory power of the model. For this, it is important to analyze the participation determinants in economic activity for men and women separately (Table 5).

Table 5

Results of the Comparative Analysis (Men/Women)

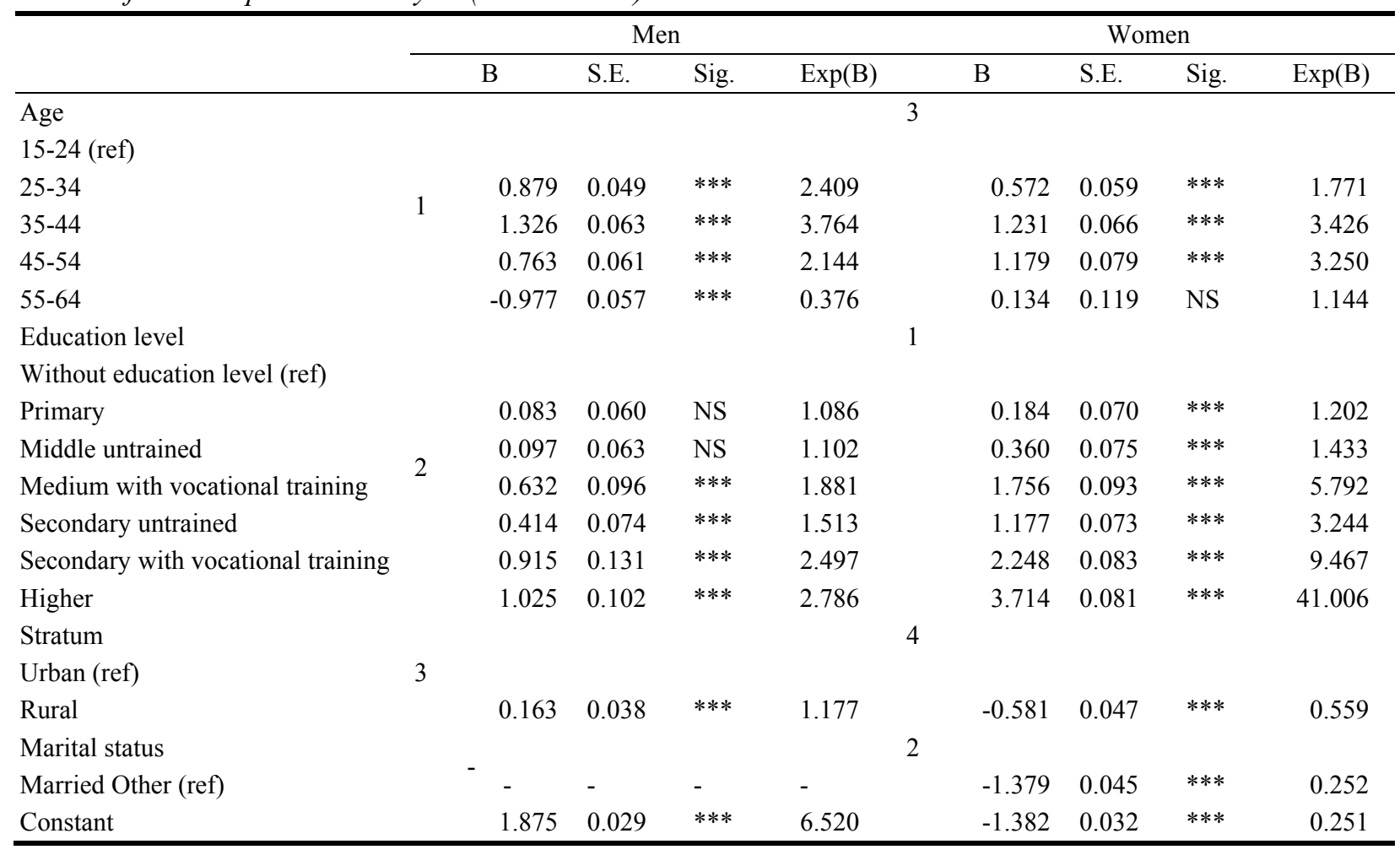

Notes. *** Significant at 5\%; NS: not significant. Source: National Statistics Office (2007).

Before interpreting results, it is important to note that in Algeria women activity is underestimated especially in censuses. This is a form of employment. This comparative analysis allows to see that the individual characteristics influence for economic participation in activity is different depending on the sex of the person. For women, the variable that explains the participation or people not in economic activity is the variable relative to human capital: education level. In contrast, for men, it is the age variable that comes first followed by education level variable.

The probability that a woman is active increases with the evolution of its education level, the effect is greater for women than for men. It is important to note that women who have medium education level and have received vocational training are more likely to be active compared to those who have no training, same thing for those with secondary education and who have received vocational training. Women living in urban areas unlike men are more likely to be active compared to those living in rural areas. For men, those living in urban areas were 1.17 times less likely to be active compared to those living in rural areas. This is probably the fact that men who live in rural areas are less covered by social security and then they stay more in the job market than those living in urban areas. For the age variable, authors find that young women aged between 15 and 24 
have the lowest probability to be active. For men, it is young (15-24 years) and seniors (55-64 years) who have the lowest probability to be active. For seniors, it is the legal age for retirement.

The probability for women to be active increases for those aged between 25 and 44, then it decreases for those aged between 45 to 64 years. For men, authors find that the probability to be active is greater for those aged between 35 and 44. For women, authors introduced the variable marital status to verify the hypothesis that married women have less chance to be active. The results obtained allow to see that married women have four times less chance to be active against other women. Married women without children were 4.27 times less likely to be active. The probability increases for married women with one child (4.90) and for married women with more than one child (5.32) compared to women of the fourth modality. This confirms hypothesis, that the presence of young children in the household is an obstacle to the participation of women. The probability of women participation in economic activity decreases in the presence of young children in the household.

\section{Labor Demand Analysis}

In this part, firstly authors analyze the role of individual characteristics in the tenure choice and secondly determine the individual's characteristics in each segment of the labor market. For this, authors applied a multi-variate econometric technique "segmentation" on the occupied population aged between 15 and 64 of the employment survey 2007. Authors constructed 12 segments from the variables: activity sector, legal sector, employment status, main activity, a registration form, and affiliation to social security. The following Figure 2 illustrates the construction segments approach.

Econometric modeling results. The results of this analysis allowed to say that education is the most important factor in the choice of tenure. Overall, authors find that young men aged between 15 and 29 years with an education level below secondary level (no education, primary and medium) are more in the segments "agricultural employment" and "wage undeclared". Those living in rural areas are more in agricultural employment and those living in urban areas are more in the segment "wage undeclared". For women with the same profile, authors find that the number is more in the segments "agricultural employment", "informal self-employment", and "unpaid worker". The number is more in agricultural employment for those living in rural areas and for those living in urban areas, more in the segment "informal self-employment" and the "unpaid worker". However, for persons aged 30 and over with secondary education and higher education, the number is more in the segments "public firm" and "administration" for both men and women. Nevertheless, it is important to note that the weight of women in the segment "administration" is more important than men. In contrast, men are more in the public firm segment than women. In trying to detail the results, authors find that men with no education whatever their age is are more occupied in the agricultural segment, and the more they advance in age, less this segment is primarily for the benefit segments undeclared salaries and informal self-employment. However, uneducated women aged fewer than 25 are more in the segment "agricultural sector". Those aged 25 and older are in the segment "informal employment". People with primary education aged between 15 and 19 years living in urban areas as opposed to rural areas (which are in the segment "agricultural employment") are more in the segment "salaried undeclared". Men with primary aged between 20 and 24 are in segments "agricultural employment" and "undeclared salaries". Women with the same profile are in informal self-employment and segments unpaid worker. Men with the same level of education aged 25 and over are in segments undeclared wage employment in agriculture and unlike women who are in informal employment segment. 


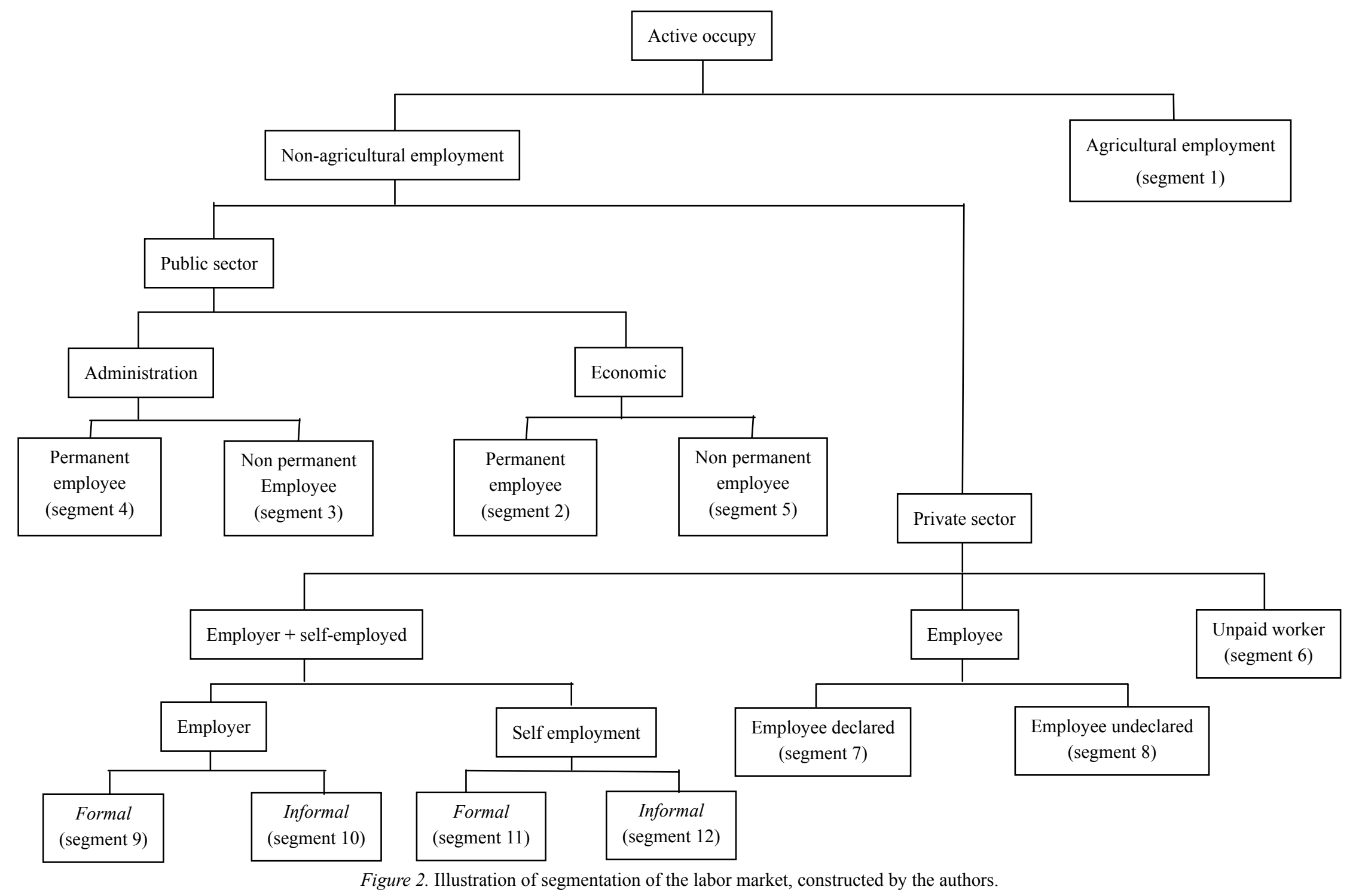


People with medium educational level between 15 and 19 years living in urban areas as opposed to rural areas (which are in the "agricultural employment" segment) are more in the salaried undeclared segment. Men aged between 20 and 24 are more in the salaried undeclared segment unlike women who are in informal employment segment. People between 25 and 29 are in the undeclared salaries segment regardless of their living environment (urban/rural). People aged 30 and older are in the segment "administration". The weight of women in this segment is more important than men. Men with high school aged between 15 and 19 years as opposed to women (who are in the informal self-employment segment) are in the "agricultural employment" segment. People between 20 and 24 living in urban areas as opposed to rural areas (which are in the "administration" segment due to the existence of more opportunities) are in the "wage undeclared" segment. Both men and women aged 25 and older are in the "administration" segment (more women). Finally, people aged between 20 and 24 years whether they lived in an urban or rural area are more in the "administration" segment (more for rural). For both men and women aged 25 and over, they are in the "government" segment but the number of women is greater in this segment than men.

Employment trends analysis by segments. The following Table 6 illustrates changes in employment between 1997 and 2007 for different segments of the labor market.

Table 6

Calculation of Growth Rates for Different Segments (1997-2007) Number in Thousands

\begin{tabular}{|c|c|c|c|c|c|c|c|}
\hline & & 1997 & 2007 & GR & AAGR & & \\
\hline Segments & Segments & frequency & $\%$ & frequency & $\%$ & $\%$ & $\%$ \\
\hline \multirow[t]{4}{*}{1} & Agricultural employment & 830 & 15.25 & 1,102 & 13 & 32.71 & 2.87 \\
\hline & Non-agricultural employment & 4,614 & 84.75 & 7,375 & 87 & 59.83 & 4.80 \\
\hline & Public sector & 2,599 & 47.73 & 2,949 & 34.78 & 13.46 & 1.27 \\
\hline & Administration & 1,362 & 25.02 & 2,272 & 26.8 & 66.81 & 5.25 \\
\hline 2 & Permanent employee in administration & 1,260 & 23.15 & 1,887 & 22.26 & 49.70 & 4.12 \\
\hline \multirow[t]{2}{*}{3} & No permanent employee in administration & 102 & 1.87 & 385 & 4.55 & 278.83 & 14.25 \\
\hline & Economic & 1,237 & 22.72 & 677 & 7.98 & -45.29 & -5.85 \\
\hline 4 & Permanent employee of the public economic & 1,140 & 20.95 & 531 & 6.26 & -53.45 & -7.36 \\
\hline \multirow[t]{2}{*}{5} & $\begin{array}{l}\text { Non-permanent employee of the public } \\
\text { economic }\end{array}$ & 96 & 1.77 & 146 & 1.72 & 51.23 & 4.22 \\
\hline & Private sector & 2,016 & 37.02 & 4,427 & 52.22 & 119.63 & 8.19 \\
\hline \multirow[t]{2}{*}{6} & Unpaid worker & 159 & 2.92 & 219 & 2.58 & 37.51 & 3.24 \\
\hline & Employee & 709 & 13.03 & 2,254 & 26.59 & 217.88 & 12.26 \\
\hline 7 & Private sector: declared employee & 244 & 4.49 & 541 & 6.38 & 121.16 & 8.26 \\
\hline \multirow[t]{2}{*}{8} & Private sector: undeclared employee & 465 & 8.54 & 1,714 & 20.22 & 268.76 & 13.94 \\
\hline & Employer & 97 & 1.78 & 345 & 4.07 & 255.51 & 13.52 \\
\hline 9 & Formal employer & 88 & 1.61 & 283 & 3.34 & 223.01 & 12.44 \\
\hline \multirow[t]{2}{*}{10} & Informal employer & 9 & 0.17 & 61 & 0.72 & 563.02 & 20.82 \\
\hline & Self-employment & 1,050 & 19.29 & 1,609 & 18.98 & 53.18 & 4.36 \\
\hline 11 & Formal self-employment & 492 & 9.03 & 496 & 5.85 & 0.82 & 0.08 \\
\hline \multirow[t]{2}{*}{12} & Informal self-employment & 558 & 10.26 & 1,113 & 13.13 & 99.28 & 7.14 \\
\hline & Total & 5,445 & 100 & 8,477 & 100 & 55.70 & 4.53 \\
\hline
\end{tabular}

Source: National Statistics Office (2007). 
Reading the table above, it can be seen that between 1997 and 2007, the segment that has most contributed to job creation is non-agricultural employment: The growth rate for this segment is $59.83 \%$ against $32.71 \%$ for the agricultural employment segment. The created employment by the first segment increases due to $4.80 \%$ from one year to another against $2.87 \%$ for the second segment. By analyzing non-agricultural employment segment, authors find that the private sector has created more jobs than the public sector. The growth rate of employment in the public sector is $13.46 \%$ against $119.63 \%$ in the private sector. The public sector annually contributes to the creation of employment with the rate of $1.27 \%$ against $8.19 \%$ for the private sector. By focusing on the public sector segment, authors find that the jobs created in this sector have been created exclusively by the administration with a growth rate of $66.81 \%$. The administration annually contributes to the creation of employment with $5.25 \%$.

Employment in the public firm has decreased $45.29 \%$ (the annual average rate of decline is $-5.85 \%$ ). It is important to note that most of the jobs created in the administration are non-permanent. Indeed, the number of non-permanent employees in the administration was increased by 3.79 and the number of permanent employees was multiplied by 1.50 . For the public firm, the decrease is the results of the substantial reduction of permanent employees due to downsizing after the structural adjustment program (SAP). The number of permanent employees in this segment was divided by 2; the number of non-permanent employees was multiplied by 1.51 .

For the private sector segment, authors find that the jobs created in this sector have been more in the form of salaried, the number of employees in this sector has been multiplied by 3.18 , but the job was created more as a undeclared employee. The growth is $268.76 \%$ and the average annual growth rate is $13.94 \%$. The number of unregistered workers in the private sector has increased by 3.69 against those multiplied by 2.21 . The employer's number has been multiplied by 3.56 , but by distinguishing between formal and informal employers, authors find that the employer's number has involved more informal employers than formal ones. Indeed, the number of informal employers has increased by 6.63 , but for formal employers it was multiplied by 3.23 .

For self-employment, authors find that their number was multiplied by 1.53 . The number of informal self-employed has developed more than formal self-employed; the first has been multiplied by 1.01 and the second by 1.99 . From the analysis (Table 7) conducted on the population with higher educational level, it can be seen that the segment where the workforce has changed in this period is "non-permanent employees in the administration" segment. The number of jobs in this segment was multiplied by 14.83 ; this is due to different active labor market policies. Authors therefore find that these programs have not enabled the integration of graduates in significant numbers both in the public firm nor the private sector and even in the "administration" sector; they are more in employee segment as non-permanent than permanent because of their status.

This analysis of employment trends in segments between 1997 and 2007 allows to reach the conclusion that the employment situation in Algeria in this period has deteriorated in terms of job security or decent work as defined by the ILO. Indeed, authors found that the public sector contributes little to job creation and administration is the biggest contributor in creating non-permanent jobs. Informal firms have reached significant proportions in the economic fabric of countries as well as unregistered jobs. 
Table 7

Calculation of Growth Rates for Each Segment Between 1997 and 2007 (Higher Education)

\begin{tabular}{|c|c|c|c|c|c|c|c|c|c|}
\hline & & 199 & & & 2007 & & & & \\
\hline Segments & Segments & Frequency & Weight & $\%$ & Frequency & Weight & $\%$ & $\mathrm{TC}$ & TCAM \\
\hline \multirow[t]{4}{*}{1} & Agricultural employment & 7 & 1.77 & 1.8 & 17 & 1.63 & 1.63 & 149.33 & 9.57 \\
\hline & Non-agricultural employment & 386 & 98.23 & 98.2 & 1,050 & 98.37 & 98.37 & 171.97 & 10.52 \\
\hline & Public Sector & 316 & 80.40 & 80.4 & 760 & 72.36 & 71.18 & 140.43 & 9.17 \\
\hline & Administration & 204 & 52 & 52 & 628 & 82.70 & 58.87 & 207.44 & 11.89 \\
\hline 2 & $\begin{array}{l}\text { Permanent employee in the } \\
\text { administration }\end{array}$ & 197 & 50.07 & 50.1 & 516 & 82.16 & 48.36 & 162.29 & 10.12 \\
\hline \multirow[t]{2}{*}{3} & $\begin{array}{l}\text { Non-permanent employee in the } \\
\text { administration }\end{array}$ & 8 & 1.92 & 1.9 & 112 & 17.84 & 10.50 & $1,383.40$ & 30.96 \\
\hline & Economic & 112 & 28.40 & 28.4 & 131 & 17.30 & 12.31 & 17.73 & 1.65 \\
\hline 4 & $\begin{array}{l}\text { Permanent employee of the public } \\
\text { economic }\end{array}$ & 107 & 27.26 & 27.3 & 105 & 79.89 & 9.84 & -2.02 & -0.20 \\
\hline \multirow[t]{2}{*}{5} & $\begin{array}{l}\text { Non-permanent employee of the } \\
\text { public economic }\end{array}$ & 4 & 1.14 & 1.1 & 26 & 20.11 & 2.48 & 491.34 & 19.45 \\
\hline & Private Sector & 70 & 17.83 & 17.8 & 290 & 27.64 & 27.19 & 314.19 & 15.27 \\
\hline \multirow[t]{2}{*}{6} & Unpaid worker & 1 & 0.32 & 0.3 & 11 & 3.87 & 1.05 & 801.39 & 24.59 \\
\hline & Employee & 26 & 6.73 & 6.7 & 145 & 49.83 & 13.55 & 446.39 & 18.51 \\
\hline 7 & Private sector: declared employee & 16 & 4.05 & 4 & 89 & 61.67 & 8.36 & 460.47 & 18.81 \\
\hline \multirow[t]{2}{*}{8} & Private sector: undeclared employee & 11 & 2.69 & 2.7 & 55 & 38.33 & 5.19 & 425.18 & 18.04 \\
\hline & Employer & 18 & 4.55 & 4.6 & 63 & 43.87 & 5.94 & 254.56 & 13.49 \\
\hline 9 & Informal employer & 1 & 0.24 & 0.2 & 2 & 2.61 & 0.16 & 73.46 & 5.66 \\
\hline \multirow[t]{2}{*}{10} & Formal employer & 17 & 4.31 & 4.3 & 62 & 97.39 & 5.79 & 264.78 & 13.82 \\
\hline & Self-employment & 24 & 6.22 & 6.2 & 71 & 49.04 & 6.64 & 189.92 & 11.23 \\
\hline 11 & Informal self-employment & 8 & 2.07 & 2.1 & 21 & 30.13 & 2 & 162.72 & 10.14 \\
\hline \multirow[t]{2}{*}{12} & Formal self-employment & 16 & 4.15 & 4.2 & 50 & 69.87 & 4.64 & 203.47 & 11.74 \\
\hline & Total & 393 & 100 & 100 & 1,067 & 100 & 100 & 171.56 & 10.51 \\
\hline
\end{tabular}

Source: National Statistics Office (2007).

\section{Operation Analysis of the Labor Market}

Impact of individual characteristics for participation in economic activity. In this step, authors worked only on active population in order to determine the individual's characteristic effect of family membership for the occupied population. For this, authors isolated the unemployed population from the active and have applied the same technique used in the first step.

Econometric modelling (Table 8) has highlighted the age variable as the primary factor that determines the occupied in the labor market. All things being equal, young people aged between 15 and 24 years are most at risk to be unemployed. The probability of being employed increases with age, which is 1.92 times higher for people aged between 25 and 34 years. It increases for those aged between 35 and 44 (5.76), for those aged between 45 and 54 (10.18), and for those aged between 55 and 64 years compared with people aged between 15 and 24.

Individuals who have received vocational training either in a training public center or private are more at risk of being unemployed compared to those who have not received vocational training.

This probability is 1.57 times less for those who were trained in a public center and it is 1.53 times less for those who have completed training in a private center. The probability of finding a job decreases with the level of education (phenomenon of graduate unemployment). 
Table 8

Probability of Belonging to the Employed Category vs. Unemployed

\begin{tabular}{|c|c|c|c|c|}
\hline & $\mathrm{B}$ & S.E. & Sig. & $\operatorname{Exp}(B)$ \\
\hline \multicolumn{5}{|l|}{ Age } \\
\hline \multicolumn{5}{|l|}{$15-24$ (ref) } \\
\hline $25-34$ & 0.653 & 0.042 & $* * *$ & 1.922 \\
\hline $35-44$ & 1.752 & 0.062 & $* * *$ & 5.767 \\
\hline $45-54$ & 2.320 & 0.098 & $* * *$ & 10.181 \\
\hline $55-64$ & 2.804 & 0.206 & $* * *$ & 16.503 \\
\hline Vocational training & -0.455 & 0.049 & & 0.634 \\
\hline Yes public school & -0.427 & 0.109 & $* * *$ & 0.653 \\
\hline Yes private school & & & $* * *$ & \\
\hline \multicolumn{5}{|l|}{ No (ref) } \\
\hline \multicolumn{5}{|l|}{ Education level } \\
\hline Illiterate & 0.707 & 0.109 & $* * *$ & 2.027 \\
\hline Primary & 0.253 & 0.069 & $* * *$ & 1.288 \\
\hline Medium & 0.229 & 0.063 & $* * *$ & 1.258 \\
\hline Secondary & 0.280 & 0.065 & $* * *$ & 1.323 \\
\hline \multicolumn{5}{|l|}{ Superior (ref) } \\
\hline \multicolumn{5}{|l|}{ Sex } \\
\hline \multicolumn{5}{|l|}{ Male (ref) } \\
\hline Female & -0.288 & 0.051 & $* * *$ & 0.750 \\
\hline Constant & 2.215 & 0.060 & $* * *$ & 9.161 \\
\hline
\end{tabular}

Note. *** Significant at the 5\%. Source: National Statistics Office (2007).

Table 9

Comparative Analysis Results (Men/Women)

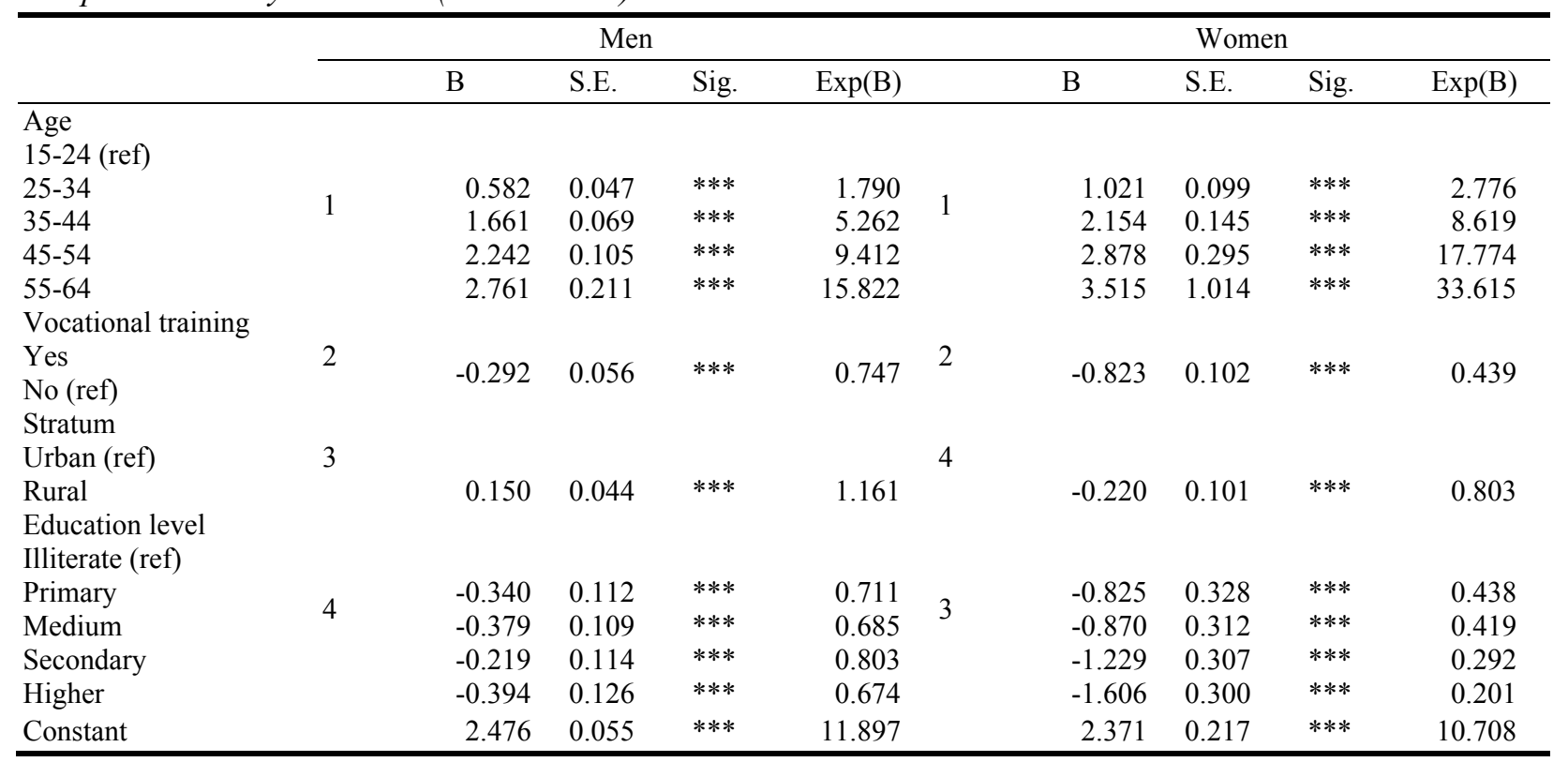

Note. $* * *$ Significant at 5\%. Source: Authors processing of Employment Survey 2007 (NOS).

The comparative analysis (Table 9) allows to note that age is the primary factor that determines the employed in the labor market. Vocational training is significant with negative effect for participation in the 
labor market for those who have trained with a greater effect for women. The probability of being employed decreases with the education evolution for men or women. Women living in rural areas unlike men are less likely to be employed compared to those living in urban areas.

Finally, it is important to note that from the two analysis results (active vs. inactive and employed vs. unemployed), the variable sex has a great effect on the first phase of economic activity participation. However, this variable has no significant effect on the second phase of real participation in economic activity (being employed).

\section{Recruitment Mode (Channel) of Employees in Algeria}

To understand the labor market situation in Algeria, it is important to analyze the methods used by employee to obtain jobs.

The following Table 10 shows the employees distribution of public and private sectors recruited between 2003 and 2007 according to different modes (channels) of recruitment.

Table 10

Employees Recruited Distribution Between 2003 and 2007 According to the Recruitment Methods

\begin{tabular}{|c|c|c|c|c|c|c|}
\hline \multirow{2}{*}{ Methods of recruitment } & \multicolumn{2}{|l|}{ Total } & \multicolumn{2}{|l|}{ Men } & \multicolumn{2}{|l|}{ Women } \\
\hline & Frequency $\left(10^{3}\right)$ & $\%$ & Frequency $\left(10^{3}\right)$ & $\%$ & Frequency $\left(10^{3}\right)$ & $\%$ \\
\hline In responding to an annonce & 173 & 6.9 & 122 & 5.9 & 51 & 11.3 \\
\hline Personal or family relation & 1,207 & 48.1 & 1,068 & 51.8 & 139 & 31.1 \\
\hline Competition or examination & 256 & 10.2 & 182 & 8.8 & 73 & 16.4 \\
\hline Contacted by employer & 490 & 19.5 & 450 & 21.8 & 40 & 9.1 \\
\hline Affected by the school after the training & 52 & 2.1 & 33 & 1.6 & 19 & 4.3 \\
\hline Public agency for placement (ANEM) & 220 & 8.8 & 112 & 5.4 & 108 & 24.2 \\
\hline Other & 112 & 4.4 & 96 & 4.7 & 16 & 3.6 \\
\hline Total & 2,510 & 100 & 2,063 & 100 & 446 & 100 \\
\hline
\end{tabular}

Source: National Statistics Office (2007).

From the table above, it can be seen that:

- Over $48 \%$ of employees have been recruited by personal or family relationship with an important difference between men and women. Over $51 \%$ of men were recruited by those against $31 \%$ for women with a ratio of 7.68 times for men;

- For men, the important recruitment methods are: personal or family relationships $(51.8 \%)$ and contacted by an employer (19.5\%). For women, it channels personal or family relationships (31.1\%), ANEM placement (24.2\%), and competitions or exams (16.4\%);

- The ANEM placement part is relatively low. This part is $8.8 \%$ or 220,000 placement. The men proportion placed by this agency is relatively low (5.4\%) compared to women $24.2 \%$.

The following Table 11 shows the employees distribution recruited between 2003 and 2007 with higher levels of education by recruitment and sex mode.

Employee's men with higher education levels were recruited mainly through competition or exam $(32.2 \%)$ and by personal or family relationship (28.1\%). For women, it is more by competition channels or exams (26.7\%) and by the ANEM (22.8\%). For ANEM placement, it is important to know what legal sector and in which labor market segments these placement have been made. 
The following Table 12 shows the employees hired distribution between 2003 and 2007 with higher education levels by mode of recruitment, legal sector, the "labor market" segments and gender.

Table 11

Distribution of Employees With Higher Levels of Education by Recruitment and Sex Mode

\begin{tabular}{lcccc}
\hline & \multicolumn{2}{c}{ Men } & \multicolumn{2}{c}{ Women } \\
\cline { 2 - 5 } & Frequency $\left(10^{3}\right)$ & $\%$ & Frequency $\left(10^{3}\right)$ & $\%$ \\
\hline In responding to an annonce & 23 & 10.3 & 32 & 15.5 \\
Personal or family relation & 62 & 28.1 & 38 & 18.4 \\
Competition or examination & 71 & 32.2 & 55 & 26.7 \\
Contacted by employer & 23 & 10.3 & 15 & 7.3 \\
Affected by the school after the training & 12 & 5.2 & 14 & 6.9 \\
Public agency for placement (ANEM) & 20 & 9 & 57 & 22.8 \\
Other & 11 & 4.9 & 206 & 2.4 \\
Total & 222 & 100 & & 100 \\
\hline
\end{tabular}

Source: National Statistics Office (2007).

Table 12

Distribution of ANEM Investment for Employees With a Higher Level

\begin{tabular}{|c|c|c|c|c|c|c|c|}
\hline \multirow[b]{2}{*}{ Variables } & \multirow[b]{2}{*}{ Terms } & \multicolumn{2}{|c|}{ Total } & \multicolumn{2}{|c|}{ Men } & \multicolumn{2}{|c|}{ Women } \\
\hline & & $\begin{array}{l}\text { Frequency } \\
\left(10^{3}\right)\end{array}$ & $\%$ & $\begin{array}{l}\text { Frequency } \\
\left(10^{3}\right)\end{array}$ & $\%$ & $\begin{array}{l}\text { Frequency } \\
\left(10^{3}\right)\end{array}$ & $\%$ \\
\hline \multirow{3}{*}{ Legal sector } & Public & 64 & 94.6 & 17 & 85 & 46 & 97.9 \\
\hline & Private & 4 & 5.4 & 3 & 15 & 1 & 2.1 \\
\hline & Total & 67 & 100 & 20 & 100 & 47 & 100 \\
\hline \multirow{6}{*}{$\begin{array}{l}\text { Segments of } \\
\text { the labor } \\
\text { market }\end{array}$} & $\begin{array}{l}\text { Permanent employees in the public } \\
\text { administration }\end{array}$ & 9 & 12.9 & 1 & 5 & 8 & 17 \\
\hline & $\begin{array}{l}\text { Non-permanent employees in the public } \\
\text { administration }\end{array}$ & 46 & 68.3 & 10 & 50 & 34 & 72.3 \\
\hline & Permanent employees in public firm & 2 & 3.6 & 2 & 10 & 1 & 2.1 \\
\hline & Non-permanent employees in public firm & 7 & 9.8 & 4 & 20 & 3 & 6.4 \\
\hline & Private sector employees & 4 & 5.4 & 3 & 15 & 1 & 2.2 \\
\hline & Total & 68 & 100 & 20 & 100 & 47 & 100 \\
\hline
\end{tabular}

Source: National Statistics Office (2007).

Almost all (over 94\%) of ANEM placements for employees with higher education levels are in the public sector. In administration, over $68 \%$ were recruited as non-permanent employees and $13 \%$ as permanent employees. In the economic public sector, 9.8\% were recruited as non-permanent employees and less than 4\% as permanent employees. By comparing analysis between men and women, it can be seen that the proportion of ANEM placements for women with higher educational level is higher in the "administration" segment, either as permanent employees or as non-permanent employees compared to men of the same educational level. For men, the proportions are greater in the other segments: non-permanent employees in administration and non-permanent employees in the economic public sector. These results challenge the effectiveness of ALMP to support the employability of higher graduates. Indeed, ANEM place little graduates in the private sector $(5.4 \%)$, it invests more in the public sector but not as permanent employees, which challenges the job quality.

The following Table 13 shows the employees distribution by main occupation and experience. 
Table 13

Distribution of Employees by Main Occupation and Experience

\begin{tabular}{lccccc}
\hline & \multicolumn{5}{c}{ Experience } \\
\cline { 2 - 6 } & Before 1992 & $1993-1997$ & $1998-2002$ & $2003-2007$ & Total \\
\hline Senior officials & 7.1 & 13.5 & 12.1 & 10.3 & 9.6 \\
Intellectual and scientific professions & 22.5 & 23.5 & 33.6 & 43.5 & 28.5 \\
Associate professionals & 29.5 & 30.5 & 35.3 & 35 & 31.6 \\
Clerks & 14.8 & 5.7 & 3 & 1.5 & 8.8 \\
Service workers and shop and market & 12.5 & 11.9 & 4.8 & 1.6 & 9.1 \\
Farmers and skilled agricultural and fishery & 0.9 & 1.7 & 1.9 & 0.7 & 1.1 \\
Industrial workers and trades & 3.3 & 2.7 & 1.1 & 0.9 & 2.4 \\
Plant and machinery & 1.1 & 1.1 & 1.1 & 0.2 & 0.9 \\
Laborers and unskilled workers & 8.3 & 9.4 & 7.1 & 6.3 & 8 \\
Total & 100 & 100 & 100 & 100 & 100 \\
\hline
\end{tabular}

Source: National Statistics Office (2007).

Reading the table above, it can be seen that the employees recruited before 1992 occupied the following professions: intellectual and scientific profession (43.5\%), intermediate profession (35\%), senior officials and managers (10.3\%). Those who were recruited in the last five years between 2003 and 2007 are less represented in these three profession, the proportions were significantly decreased by cons found in administration (14.8\%) and personnel (12.5\%). This clearly means that there is deterioration in the employment quality for people with a higher level or more precisely a disqualification.

\section{Conclusions}

The youth inclusion in active life is for a long time a recurrent society problem, often lived hard by young people and their families. Despite increasing resources mobilized by the government, the unemployed young people proportion remains permanently important in fact. This situation carried in a context of high tension on the labor market. The labor supply analysis allows to see that the new cohorts pursue their studies and go more and more universities as opposed to older generations. This means that there are more and more educated people coming to the labor market. On the other hand, men participation in economic activity follows logic quite different from the participation of women. In fact, for men the age is the variable that determines the participation in the labor market, by contrary for women, it is the education level and vocational training that determine the participation in labor market. Closely following an academic or vocational training, it has a positive impact on women participation rates. The analysis of labor demand found that young people are the most exposed group to insecurity on the job market. Human capital is an important factor in positioning various segments of the labor market and improving the job situation. Therefore, the probability of occupating a protected work increases with the level of education. From these two points, there is the discrimination against youth and persons with low educational attainment and even for those with a medium level for the protected work occupation. The occupation conditions and position in different segments of the labor market differ significantly by sex. The analysis of employment trends in segments between 1997 and 2007, allows to reach the conclusion that the employment situation in Algeria during this period has deteriorated in terms of employment security or decent job as defined by the ILO. From the functioning analysis of the labor market, it found that age was the variable that first determines participation in the labor market. Young people aged 
between 15 and 24 years are most at risk of unemployment. Individuals who have received vocational training are most at risk of unemployment compared to those not trained. Individuals with education below medium are more likely to be employed compared to those with a medium level. In contrast, those with education level higher than medium are at greater risk of unemployment, this is due to the mismatch between followed training and the request of the labor market. There is deterioration in the employment quality for people with a higher level or more precisely a disqualification (unskilled). On one hand, there are more and more educated people entering the labor market and on the other hand, jobs created are increasingly unskilled. This calls into question that the whole discourse and politics aimed at improving the young employability entrants to the labor market.

This work has enabled to determine the impact of human capital, the role of other individual factors for participation in the labor market, and the individuals occupational choice; but it is important to deep on the work taking into account other factors such as: household characteristics, factor earnings, and the country macroeconomic context which may affect the employability and individuals occupational choice in a market increasingly segmented.

\section{References}

Arrow, K. J. (1973). Higher education as filter. Journal of public economics, 2, 192-216.

Becker, G. (1993). Human capital: A theoretical and empirical analysis (3rd ed.). Chicago: University of ChicagoPress.

Brilleau, A., Roubaud, F., \& Torelli, C. (2004). L'emploi, le chômage et les conditions d'activité dans les principales agglomérations de sept Etats membres de l'UEMOA (Document de travail DIAL. DT 2004-06).

Chevalier, A., \& Viitanen, T. K. (2001). The long run consequences of teenage motherhood in Britain (Version 51, London School of Economics Working Papers, Hougton, Warwick University).

Desai, S., \& Waite, L. (1991). Women's employment during pregnancy and after the first birth: Occupational characteristics and work commitment. American Sociological Review, 56(4), 551-566.

Eicher, J. C. (1979). Economics of education. Paris: Economica.

Kouamé, A. (1999). Education et Emploi des femmes à Abidjan: Chapitre1-Collection Sociétés Africaines et DiasporaL'Harmattan (Education and employment of women in Abidjan, Chapter 1-Collection African Societies and Diaspora).

Kuépié, M., Nordman, C. J., \& Roubaud, F. (2006). Education and labour market outcomes in Sub-Saharan Africa (Document de Travail DIAL, DT 2006-16).

Lachaud, J. P. (1998). Modélisation des déterminants de la pauvreté et marché du travail en Afrique: le cas du Burkina Faso (Modeling of the determinants of poverty and the labor market in Africa: the case of Burkina Faso, Working Paper No. 32, Development Economics Centre, University Montesquieu Bordeaux IV).

Lazear, E. P. (1981). Agency, earning profiles, productivity and hours restriction. American Economic Review, 71(4), 606-620.

Mincer, J. (1974). Schooling, experience and earnings. New York: National Bureau of Economic Research.

National Statistics Office. (2007). Statistical collections, social statistics, labor force survey 2007 (No. 139, December 2007, Algeria). Retrieved from http://www.ons.dz/-Emploi-et-chomage-.html

National Statistics Office. (2013). Statistical collections, social statistics, labor force survey 2013 (No. 653, December 2013, Algeria). Retrieved from http://www.ons.dz/-Emploi-et-chomage-.html

Newel, M., \& Joshi, H. (1986). The next job after the first baby occupational transition among women born in 1946 (Centre for Population Studies, Working paper, 86-3).

Perry, S. (1988). Downward occupational mobility and part-time women workers. Applied Economics, 20(1), 485-495.

Psacharopoulos, G., \& Patrinos, H. A. (2004). Returns to investment in education: A further update. Education Economics, 12(2), 111-134.

Rönsen, M., \& Sunström, M. (1996). Maternal Employment in Scandinavia: A comparison of the after-birth employment active of Norwegian and Swedish Women. Journal of Population Economics, 9, 267-285.

Schultz, T. P. (2004). Evidence of returns to schooling in Africa from household surveys: Monitoring and restructuring the market for education. Journal of African Economies, 13, 95-148. 
Smith-Lovin, L., \& Tickamyer, A. K. (1978). Nonrecursive models of labour force participation, fertility behaviour and sex role attitudes. American Sociological Review, 43(4), 541-557.

Spence, M. (1973). Job market signalling. Quarterly journal of economics, 87, 355-375.

Spence, M. (1974). Market signalling: Informational transfer in hiring and related processes. Cambridge: Harvard University Press.

Tremblay, D. G. (1997). Labour economics; realities and theoretical approaches. Montreal: Editions St Martin.

Vernières, M. (1997). L'insertion professionnelle: analyse et débats (The professional integration, analysis and debates, France, Editions Economica).

Vincens, J. (1998). L'insertion professionnelle des jeunes, quelques réflexions théoriques (The professional integration of young people, some theoretical reflections, Training Employment, No. 61, Centre for Studies and Research on Qualifications (CEREQ), pp. 59-72).

Waite, L. J., \& Stolzenberg, R. M. (1976). Intended childbearing and labor force participation of young women: Insights from nonrecursive models. American Sociological Review, 41, 235-251.

Wetzels, C. (1999). Squeezing birth into working life: Household panel data analysis comparing Germany, Great Britain, Sweden and the Netherlands (Tinbergen Institute Research Series, Universiteit van Amsterdam). 